\title{
Modulation of CA3 Afferent Inputs by Novelty and Theta Rhythm
}

\author{
Desiree M. Villarreal, Amanda L. Gross, and Brian E. Derrick \\ Department of Biology, The University of Texas at San Antonio, San Antonio, TX 78249-0662
}

\begin{abstract}
Models of hippocampal function suggest that the modulation of CA3 afferent input during theta rhythm allows for a rapid alternation between encoding and retrieval states, with each phase enhancing either extrinsic or intrinsic CA3 afferents, favoring either encoding or retrieval, respectively. Here, we show that during the initial exploration of a novel environment by rats, intrinsic CA3-CA3 synaptic inputs are attenuated on $\mathrm{CA} 3$ theta peaks, favoring extrinsic $\mathrm{CA} 3$ inputs, whereas extrinsic perforant path-CA3 synaptic inputs are attenuated on CA3 theta troughs, favoring intrinsic CA3 inputs. This modulation is absent when animals are re-exposed to the same environment 2 or $48 \mathrm{~h}$ later and thus habituates with familiarity, suggesting a process involved in learning. Modulation of CA3 synaptic inputs during novelty was blocked by atropine at a dose that blocks type 2 theta rhythm. Re-exposure to the same novel environment $48 \mathrm{~h}$ later in the absence of atropine did not result in habituation, but instead modulated CA3 synaptic responses as though the environment were novel and explored for the first time. The NMDA receptor antagonist ( \pm )-3-(2-carboxypiperazin-4-yl)propyl-1-phosphonic acid (CPP), administered in a dose that blocks long-term potentiation induction, did not alter CA3 synaptic modulation during initial exploration. However, like atropine, CPP blocked the habituation of synaptic modulation normally observed with re-exposure, as though the environment were novel and explored for the first time. Thus, as predicted theoretically, recurrent and cortical CA3 afferents are differentially modulated during phases of theta rhythm. This modulation is atropine sensitive and habituates in an NMDA receptor-dependent manner, suggesting an NMDA receptor-dependent process that, in conjunction with theta rhythm, contributes to encoding of novel information in the hippocampus.
\end{abstract}

Key words: CA3; LTP; theta rhythm; encoding; retrieval; learning; memory

\section{Introduction}

The CA3 region of the hippocampus is thought to play an essential role in memory, as this region may act as an autoassociative device by virtue of its extensive recurrent excitatory connections that permit pattern completion and recollection (Marr, 1971; McNaughton and Morris, 1987; Treves and Rolls, 1992, 1994). Behavioral studies also implicate the CA3 region in encoding (Marr, 1971; Lee and Kesner, 2004; Moser and Moser, 2003; Nakazawa et al., 2002), and, by favoring either pattern separation or pattern completion, the CA3 region can alternate between encoding or retrieval states (Hasselmo et al., 1995; Lee et al., 2004; Leutgeb et al., 2004; Vazdarjanova and Guzowski, 2004; Guzowski et al., 2004).

A problem inherent in neural network models that perform both encoding and retrieval is encoding new information without disrupting previously stored information ("the stabilityplasticity dilemma") (Grossberg, 1987; McNaughton and Morris,

\footnotetext{
Received Aug. 14, 2007; revised 0ct. 12, 2007; accepted 0ct. 22, 2007.

This work was supported by National Institute of Neurological Disorders and Stroke Grant NS 30409 and National Institute of General Medical Sciences Grant GM 08194. We thank Dr. Brenda J. Claiborne for helpful comments on this manuscript, Floretta Jones for assistance with histology, and Dario Dieguez Jr. for pilot studies and preliminary versions of this manuscript.

Correspondence should be addressed to Brian E. Derrick, The University of Texas at San Antonio, Cajal Neuroscience Institute, Department of Biology, 6900 North Loop, 1604 West, San Antonio, TX 78249-0662. E-mail: bderrick@utsa.edu.

D0I:10.1523/JNEUROSCI.3702-07.2007

Copyright $\odot 2007$ Society for Neuroscience $\quad$ 0270-6474/07/2713457-11\$15.00/0
}

1987; O’Reilly and McClelland, 1994; McClelland et al., 1995; Rolls and Treves, 1998; Abraham and Robins, 2005). If recurrent excitatory synapses strengthened from previously encoded information influence synaptic plasticity during new encoding, such activity can corrupt both previously stored and newly encoded information (McNaughton and Morris, 1987; Hertz et al., 1991; Hasselmo and Bower, 1992; Rolls and Treves, 1998; Hasselmo et al., 2002; Hasselmo, 2005). In the pyriform cortex, one way this problem is resolved is by the selective attenuation of recurrent (intrinsic) synapses by acetylcholine during encoding so that extrinsic cortical inputs can direct plasticity (Hasselmo and Bower, 1992).

Acetylcholine also is involved in the generation of theta rhythm, a 4-12 Hz near-sinusoidal oscillation observed in the hippocampal formation (Buzsaki, 2002; Hasselmo, 2005). One way the stability-plasticity dilemma may be resolved in the hippocampus is by the separation of encoding and retrieval states on distinct phases of theta (Hasselmo et al., 1995, 2002; Kunec et al., 2005). In these models, each theta cycle involves afferent-specific changes in synaptic transmission that enhance the influence of either extrinsic (extrahippocampal) or intrinsic (recurrent or intrahippocampal) inputs during theta peaks or theta troughs. This is suggested to allow for the separation of encoding or retrieval states, respectively (Hasselmo et al., 1995, 2002; Kunec et al., 2005). Previous studies support this view, and indicate that, in the CA1 region in vivo, intrinsic Schaffer collateral-CA1 responses 
are attenuated on local theta peaks in urethane-anesthetized rats (Wyble et al., 2000). Moreover, current source density analyses reveal an alternation of perforant path and Schaffer collateral currents during theta oscillations, suggesting modulation of intrinsic and extrinsic CA1 afferent inputs synchronous with theta (Brankack et al., 1993; Kamondi et al., 1998).

Modulation of afferent inputs by theta also is thought to operate among extrinsic and intrinsic, recurrent afferents of the CA3 region (Kunec et al., 2005). Our previous studies have examined both "extrinsic" perforant path-CA3 and "intrinsic" commissural/associational (cCA3-CA3) synaptic responses in the intact animal (Do et al., 2002; Martinez et al., 2002). We used this preparation to assess modulation of CA3 synaptic responses during theta rhythm generated endogenously while exploring novel environments. Here we show that, with theta generated during exploration of novel environments, intrinsic CA3-CA3 responses are attenuated on local theta peaks, whereas extrinsic perforant path-CA3 responses are attenuated on local theta troughs, as predicted theoretically (Hasselmo et al., 1995, 2002; Kunec et al., 2005). This attenuation habituates with re-exposure to the same novel environment, suggesting an effect associated with learning. In addition, habituation was blocked by muscarinic and NMDA receptor antagonists. Thus the modulation of CA3 inputs and its habituation reflect a theta-related process in the hippocampus that, in conjunction with NMDA receptors, contributes to the encoding of new information.

\section{Materials and Methods}

Subjects. These studies were conducted in accordance with the standards established in the Guide for the Care and Use of Laboratory Animals and approved by the Institutional Animal Care and Use Committee at the University of Texas at San Antonio. Eighteen adult male Sprague Dawley rats $(400-500 \mathrm{~g} ; \sim 3-4$ months of age, Harlan, Indianapolis, IN) were individually housed on a $12 \mathrm{~h}$ light/dark cycle and had access to food and water ad libitum.

Permanent electrode implantation. Permanent electrodes were implanted as described previously (Villarreal et al., 2002; Davis et al., 2004). Briefly, rats were anesthetized with pentobarbital sodium (Nembutal, 65 $\mathrm{mg} / \mathrm{kg}$, Henry Schein, Melville, NY) with supplemental injections (10 $\mathrm{mg} / \mathrm{kg}$ ) to maintain a surgical level of anesthesia. Temperature was maintained during surgical procedures with an isothermal heating pad. Under sterile conditions, a Teflon-coated stainless-steel recording electrode (0.005 inch diameter; A-M Systems, Carlsborg, WA) was placed in the stratum pyramidale of the $\mathrm{CA} 3 \mathrm{~b}$ region of the hippocampus [anteroposterior (AP) $-3.5 \mathrm{~mm}$, mediolateral (ML) $+3.5 \mathrm{~mm}$, Dorsoventral (DV) $-3.3 \mathrm{~mm}$ ] (Paxinos and Watson, 1994; Martinez et al., 2002). Synaptic responses were evoked in the CA3 region (Fig. $1 A$ ) using bipolar electrodes made from twisted stainless-steel wires (0.005 inch diameter) placed in both the stratum radiatum of the contralateral CA3 region at a point homotopic to the CA3 recording electrode (AP $-3.5 \mathrm{~mm}, \mathrm{ML}$ $-3.5 \mathrm{~mm}$, DV $-2.5-3.0 \mathrm{~mm}$ ) (Paxinos and Watson, 1994) to evoke commissural/associational-CA3 (cCA3-CA3) responses (Derrick and Martinez, 1994), and in the dorsomedial aspect of the angular bundle to evoke medial perforant path-CA3 (mPP-CA3) responses (AP $-8.1 \mathrm{~mm}$, ML +4.1 mm, DV -2.3 mm) (McNaughton and Barnes, 1977; Paxinos and Watson, 1994; Do et al., 2002). In some animals a second recording electrode was placed in the stratum lacunosum-moleculare of the CA1 region above the hippocampal fissure (AP $-4.0 \mathrm{~mm}, \mathrm{ML}+2.5 \mathrm{~mm}$, DV $-2.5-2.8 \mathrm{~mm}$ ) (Paxinos and Watson, 1994) or in the CA3c/hilar region of the dentate gyrus (AP $-3.5 \mathrm{~mm}, \mathrm{ML}+2.0 \mathrm{~mm}, \mathrm{DV}-3.2 \mathrm{~mm}$ ) (Paxinos and Watson, 1994) to allow simultaneous recording of fissure or hilar theta rhythm, and the comparison of fissure and hilar theta with theta observed in the CA3 stratum pyramidale.

Electrodes were attached to gold amphenol pins (Small Parts, Miami Lakes, FL) mounted in plastic nine-pin MacIntyre sockets (Ginder Scientific, Ottawa, ON), and affixed to the skull with stainless steel screws and dental acrylic (Medix, Reseda, CA). Post surgery, rats were given 150,000 IU of Penicillin G (i.m.; AmTech, Fort Dodge, IA), and Rimydal $(100 \mathrm{mg} / \mathrm{d}$ for $2 \mathrm{~d}$ postsurgery; Bioserve, Frenchtown, NJ). Rats were allowed to recover for at least 2 weeks before data collection.

Collection of EEG and field EPSPs in behaving rodents. The magnitude of hippocampal synaptic responses is influenced by theta phase observed in the same hippocampal field (Wyble et al., 2000). We therefore recorded $1 \mathrm{~s}$ epochs of EEG from the CA3 pyramidal cell layer to observe local CA3 theta rhythm and any effects on evoked CA3 synaptic responses. Responses were evoked $900 \mathrm{~ms}$ into each $1 \mathrm{~s}$ EEG epoch, so that each $1 \mathrm{~s}$ EEG epoch had either an evoked mPP-CA3 or CA3-CA3 response in the last $100 \mathrm{~ms}$ of the epoch, allowing identification of responses evoked on theta peaks and troughs. Both field EPSPs and EEG were recorded from a single CA3 electrode in the stratum pyramidale within a single $1 \mathrm{~s}$ epoch. Either cCA3-CA3 or mPP-CA3 field EPSPs were evoked by stimulation of the perforant path or the contralateral CA3 region using a biphasic constant current pulse $(0.1 \mathrm{~ms} /$ phase, $100-450$ $\mu \mathrm{A}$ ) delivered at an intensity producing responses that were $\sim 50 \%$ of the asymptotic (maximal) slope response. Each EEG epoch with cCA3-CA3 or $\mathrm{mPP}-\mathrm{CA} 3$ evoked response were collected alternately at a rate of 0.167 $\mathrm{Hz}$ for each stimulation site $(0.333 \mathrm{~Hz}$ total stimulation rate), amplified $(1000 \times)$, filtered at $0.3 \mathrm{~Hz}-10 \mathrm{kHz}$, digitized ( $1 \mathrm{~s}$ at $8.6 \mathrm{kHz}$ ) and stored for off-line analysis using commercially available software (Datawave Technologies, Berthoud, CO).

Stimulation was not phase locked with ongoing theta rhythm, allowing for a random evocation of responses on various phases of endogenous theta rhythm (Wyble et al., 2000). The selection of evoked responses falling on either CA3 theta peaks or troughs within the $1 \mathrm{~s}$ EEG epoch was determined off-line, and responses were included for analysis only when (1) fast Fourier transforms (FFT) analyses revealed the frequency of maximal power (millivolts per squared millisecond) in the theta range (4-12 $\mathrm{Hz}$ ) within a $1-50 \mathrm{~Hz}$ band, (2) stimulation artifacts fell within a $60 \mathrm{~ms}$ window $30 \mathrm{~ms}$ before or after the maximum point of each theta peak or the minimum point of each theta trough (see Fig. $1 B$ ), and (3) at least 10 responses occurred on both CA3 theta peaks and troughs in each animal in each environmental condition.

To assess the effect of theta phase on cCA3-CA3 or mPP-CA3 field EPSP responses, the magnitude of slopes (millivolts per millisecond) of responses falling on either CA3 theta peaks or CA3 theta troughs were averaged over the first $20 \mathrm{~min}$ in the novel environment. Average theta peak and trough response magnitudes were then compared with the average magnitude of responses collected in the familiar (home) cage (baseline responses representing 100\% response magnitude). Peak and trough response amplitudes are presented as a percentage ( \pm SEM) of the average magnitude of home cage baseline responses, and were compared using a repeated-measures (RM) one-way ANOVA and post hoc Tukey's tests (Keppel and Zedeck, 1991).

In addition to raw EEG, EEG was filtered $(0.1 \mathrm{~Hz}-0.1 \mathrm{kHz})$ and recorded simultaneously, reducing high-frequency activity typically seen in the CA3 pyramidal layer, and aiding in the identification of theta peaks and troughs for analysis (Orr et al., 2001). Theta also was recorded simultaneously in the CA3c/dentate hilus region or the hippocampal fissure ( $\sim 500-700 \mu \mathrm{m}$ below the CA1 pyramidal cell layer) to compare local CA3 theta with theta observed at the fissure and hilar/CA3c sites $(n=8)$.

For spectral analysis of raw EEGs, the power of EEG (squared millivolts) within the theta frequency range $(4-12 \mathrm{~Hz})$ was assessed in each $1 \mathrm{~s}$ epoch using discrete FFTs (DataWave Technologies, Berthoud, CO). Measures of theta were calculated from averaged FFT of each $1 \mathrm{~s}$ epoch over the initial $20 \mathrm{~min}$ in each environmental condition (200 $1 \mathrm{~s}$ epochs from a single channel averaged for each animal in each condition). EEG was collected after placement in either novel cages, familiar cages, or the animal's home cage. Fourier estimates of theta power, the frequency of maximal power, and percentage of total power (1-50 Hz bandwidth) within each theta frequency $(4-12 \mathrm{~Hz})$ was assessed for each $1 \mathrm{~s}$ EEG epoch. Measures of total power, percent power of frequencies within the theta band $(4-12 \mathrm{~Hz})$, and frequency of maximal power from averaged FFTs were compared within animals in novel environments and familiar environments using a two-way RM ANOVA.

In studies assessing the effects of NMDA or muscarinic receptor an- 
tagonists on CA3 synaptic modulation, drugs were dissolved in sterile ultrapure water and administered i.p. either $90 \mathrm{~min}[( \pm)-3-(2-$ carboxypiperazin-4-yl)propyl-1-phosphonic acid (CPP; 3 or $10 \mathrm{mg} / \mathrm{kg}$ ] or $60 \mathrm{~min}$ (atropine sulfate, $50 \mathrm{mg} / \mathrm{kg}$; both from Tocris, Ellisville, MO) before the initial exploration of a novel environment.

Similar analyses of EEG were used to determine the effects of a 50 $\mathrm{mg} / \mathrm{kg}$ dose of atropine sulfate, or a 3 or $10 \mathrm{mg} / \mathrm{kg}$ doses of CPP, on EEG and theta rhythm. EEG was collected 90 min after administration of CPP ( 3 or $10 \mathrm{mg} / \mathrm{kg}$ ) or $1 \mathrm{~h}$ after administration of atropine sulfate $(50 \mathrm{mg} / \mathrm{kg}$ ) during the first $20 \mathrm{~min}$ of a $30 \mathrm{~min}$ period of exploring a novel environment. Measures were compared with responses collected in animals exploring a novel environment after treatment with the water vehicle. FFTs of $1 \mathrm{~s}$ EEG epochs collected over the first 20 min period of exploration were averaged and analyzed as above, and average total power, percentage of theta power, percentage of power at each frequency, and frequency of maximal power were averaged for each drug, and compared with vehicle control using a two-way ANOVA and post hoc Tukey's tests.

Novel environments elicit exploration and theta rhythm, thought to reflect a sustained period over which the animal is acquiring new information (Davis et al., 2004). Novel environments were made from Plexiglas cages identical in size to the home cage $(47 \times 25 \times 20 \mathrm{~cm})$ and included fresh bedding and $4-5$ plastic or metal objects, such as boxes and small toys. Objects were permanently mounted on the cage floor to maintain the configuration of objects within each cage. Novel cages were wiped down with ethanol before each use, except in habituation experiments, where novel cages were unaltered after initial exploration.

Exploratory behaviors include a number of diverse actions, including locomotion. As increased locomotor activity can increase the generation of theta rhythm (Vanderwolf, 1969), we measured the overall activity of each rat during each of multiple 30 -min recordings done in either a familiar or novel environment using an activity monitor (Videomex-V; Columbus, Columbus, $\mathrm{OH}$ ) which acquires and analyzes movement by a pixel-by-pixel analysis of contrast changes within the entire cage area $\left(47 \times 25 \mathrm{~cm}\right.$, with a resolution of 1000 pixels $\left./ \mathrm{cm}^{2}\right)$. Activity during exploration of novel or familiar environments is expressed as the total number of pixels detecting contrast change over the $30 \mathrm{~min}$ period, and is compared among conditions within each animal using a RM ANOVA, and among treatments using a one-way ANOVA.

In addition to analysis of the effects of CPP on EEG and theta rhythm, we also confirmed that the $3 \mathrm{mg} / \mathrm{kg}$ dose of CPP used in these studies blocks the induction of long-term potentiation (LTP) (Hernandez et al., 1994). CPP (3 mg/kg in water vehicle) or vehicle alone was administered $90 \mathrm{~min}$ before collection of baseline responses, during which either cCA3-CA3 or mPP-CA3 responses were collected for a 20 min period. LTP was then induced using four $0.5 \mathrm{~s}, 100 \mathrm{~Hz}$ trains delivered at $15 \mathrm{~s}$ intervals to either the mPP or cCA3 stimulating electrode while animals were awake. One hour later, this was repeated with the alternate pathway (with the order of the tetanized pathway counterbalanced in both vehicle and CPP groups). Potentiation was assessed by comparing response amplitudes evoked 25-30 min post-tetanus with average baseline response magnitudes $5 \mathrm{~min}$ before tetanus. The effects of CPP on LTP magnitude were compared with animals receiving only water vehicle using a oneway ANOVA.

Correct electrode placements were verified by stereotaxic coordinates, audio localization of the CA1 and CA3 pyramidal cell layers, and by histological examination of CA3 electrode placement in cresyl violetstained sections from brains cryoprotected in 30\% sucrose (see Fig. 1 E). Animals with recording or stimulating electrodes that were not within the CA3 pyramidal region or fissure and hilar sites were excluded from analyses.

Experimental design. In studies assessing the effects of novel environments on intrinsic and extrinsic CA3 synaptic responses, we recorded field EPSPs evoked in both novel and familiar environments as described previously (Davis et al., 2004). Before data collection, animals were anesthetized briefly with isofluorane and connected to the recording apparatus, and placed in an isolation box while still in its home cage for a $30 \mathrm{~min}$ period to acclimate to the isolation box environment. EEG and cCA3$\mathrm{CA} 3$ and $\mathrm{mPP}-\mathrm{CA} 3$ baseline responses were then collected in $1 \mathrm{~s}$ epochs alternately at a rate of $0.167 \mathrm{~Hz} /$ pathway for an additional $30 \mathrm{~min}$ period in the animal's home cage. Rats were reoriented in their home cage before this collection period to control for any effects of handling when transferring rats from the home cage to novel environments. After the collection of baseline responses, animals were then transferred from their home cage to a novel cage and placed in the isolation box. Both cCA3$\mathrm{CA} 3$ and $\mathrm{mPP}-\mathrm{CA} 3$ responses were again collected at the same rate and current intensity for $30 \mathrm{~min}$.

Our previous studies on the effect of novel environments on LTP revealed an enhancement of LTP when induced while exploring novel environments, although this enhancement habituated once the animal became familiar with the environment (Davis et al., 2004). Our preliminary studies also suggest that the modulation of CA3 responses by theta rhythm is absent when animals were in their home cage or familiar environments (Dieguez et al., 2004). We therefore also collected EEG and evoked CA3 responses while animals re-explored the same environment either 2 or $48 \mathrm{~h}$ after the initial period of exploration to assess the effect of theta phase on CA3 responses during re-exposure to the now-familiar environment. The magnitude of field EPSP slopes (millivolts per millisecond) that fell on local theta peaks or local theta troughs were averaged over a 30 min period of re-exposure to the same novel environment 2 or $48 \mathrm{~h}$ later. Responses evoked on theta peaks and troughs were calculated as a percentage of the average magnitude of baseline responses collected again in the home cage $30 \mathrm{~min}$ before placement in the previously explored novel cage. Peak and trough response magnitudes are presented as a percent $( \pm$ SEM $)$ of the average baseline response magnitude from responses collected in the home cage, and compared using a one-way RM ANOVA and post hoc Tukey's tests (Keppel and Zedeck, 1991).

\section{Results}

Theta rhythm elicits afferent- and theta phase-specific changes in CA3 synaptic responses during novelty

\section{exploration}

When recorded from the stratum pyramidale of the CA3 region, theta rhythm is observed, although CA3 theta is smaller in amplitude than theta recorded at other hippocampal sites (Buzsaki, 1986), and was $\sim 180^{\circ}$ out of phase with theta recorded at the hippocampal fissure $(n=3)$ (Fig. $1 C$ ) and, thus, in phase with theta observed in the CA1 pyramidal layer (Fox et al., 1983; Buzsaki, 2002; Csicsvari et al., 1999; Gray and McNaughton, 2003), consistent with previous findings indicating that CA3 neuronal firing is phase locked with theta rhythm, and that CA3 and CA1 pyramidal cells fire in synchrony during locally recorded theta (Fox et al., 1983, 1986; Csicsvari et al., 1999; Kocsis et al., 1999; Buzsaki, 2002; Bland et al., 2005; Hasselmo, 2005). Theta observed in the stratum pyramidale of CA3 may be locally generated by a dipole formed by dentate mossy fiber output to the CA3 region (Buzsaki, 1986). However, theta observed in CA3 region also was observed to be in phase with theta recorded from the hilar/CA3c region $(n=4)$ (Fig. $1 C)$, and may be volume conducted from dentate/hilar region, in line with the view that the dentate/hilar region serves as a distinct intrahippocampal generator of theta (Wiig et al., 1994; Kocsis et al., 1999; Buzsaki, 2002). Thus, theta recorded in the CA3 pyramidal layer may be locally generated in CA3, or volume conducted from adjacent dentate/hilar regions. Regardless, theta rhythm observed locally in the stratum pyramidale of CA3 was $180^{\circ}$ out of phase with fissure theta, and thus in phase with local CA1 and CA3 theta (Fox et al., 1983; Brankack et al., 1993; Csicsvari et al., 1999; Buzsaki, 2002) and served as an indicator of local theta phase within the CA3 region (Bland et al., 2005), allowing for assessment of variations in CA3 synaptic responses during distinct phases of theta rhythm.

Theta rhythm recorded in behaving animals in both the CA1 and dentate regions is normally comprised of both type 1 (movement-related) and type 2 (atropine-sensitive) theta, as 
theta still can be observed after doses of atropine that block type 2 theta rhythm (Vanderwolf, 1969; Buzsaki, 2002; Gray and McNaughton, 2003). Type 2 theta is associated with sensory processing and arousal (Sainsbury et al., 1987; Gray and McNaughton, 2003) and is typically observed during alert immobility (Vanderwolf, 1969; O'Keefe and Nadel, 1978; Vanderwolf and Leung, 1983; Sainsbury et al., 1987). Although type 2 theta is reportedly difficult to elicit in rats (Gray and McNaughton, 2003), it is elicited in rats when sniffing (Gray, 1971), when presented with conditioning stimuli (Whishaw, 1972), or in response to sensory stimuli, particularly in aroused states (Sainsbury et al., 1987). Although theta rhythm was observed frequently during immobility in novel environments, theta rhythm was attenuated, but not eliminated, in novel environments by atropine sulfate $(50 \mathrm{mg} / \mathrm{kg}$, i.p.) (Fig. $1 D)$. The occurrence of theta during both immobility, as well as in the presence of atropine, together suggest that theta rhythm observed in the CA3 region is comprised of both type 1 and 2 theta rhythm.

Responses were first collected for 30 min in the home cage, and served as a baseline for response magnitudes to determine whether synaptic responses are altered during theta phases, and, if so, if this is a result of increasing or decreasing synaptic responsiveness. After placement in a novel environment, theta in the $4-12 \mathrm{~Hz}$ range was frequently observed. The generation of theta at CA3 sites was not dependent on ambulation, and often was observed when the animal was motionless or stationary and investigating objects. An analysis of evoked perforant path and cCA3-CA3 synaptic responses elicited during theta while animals explored the novel cage revealed that cCA3-CA3 EPSP slopes were significantly reduced on theta peaks when compared with both cCA3-CA3 baseline responses evoked in the home cage and cCA3-CA3 responses evoked on theta troughs ( $80 \pm 4 \%$ of baseline on theta peaks vs $104 \pm 6 \%$ on theta troughs; $F_{(2,8)}=14.6$; $p<0.01$, ANOVA, Tukey's tests; $n=5$ ) (Fig. 2). In contrast, $\mathrm{mPP}-\mathrm{CA} 3$ EPSP magnitudes were not altered on theta peaks during novelty exploration. However, $\mathrm{mPP}-\mathrm{CA} 3$ responses were reduced significantly on local theta troughs when compared with both home cage baseline responses and MPP-CA3 responses evoked on theta peaks ( $84 \pm 3 \%$ of baseline on theta troughs vs $109 \pm 3 \%$ on theta peaks $\left(F_{(2,8)}=20.6 ; p<0.01\right.$, ANOVA; $\left.n=5\right)$ (Fig. 2). These data indicate novelty exploration elicits a differential, afferent and theta phase-specific attenuation of intrinsic (cCA3-CA3) and extrinsic (mPP-CA3) synaptic responses during local theta peaks and troughs, respectively. This corresponds to the changes in afferent input that have been suggested to parcel encoding and retrieval processes (Hasselmo et al., 2002; Kunec et al., 2005).
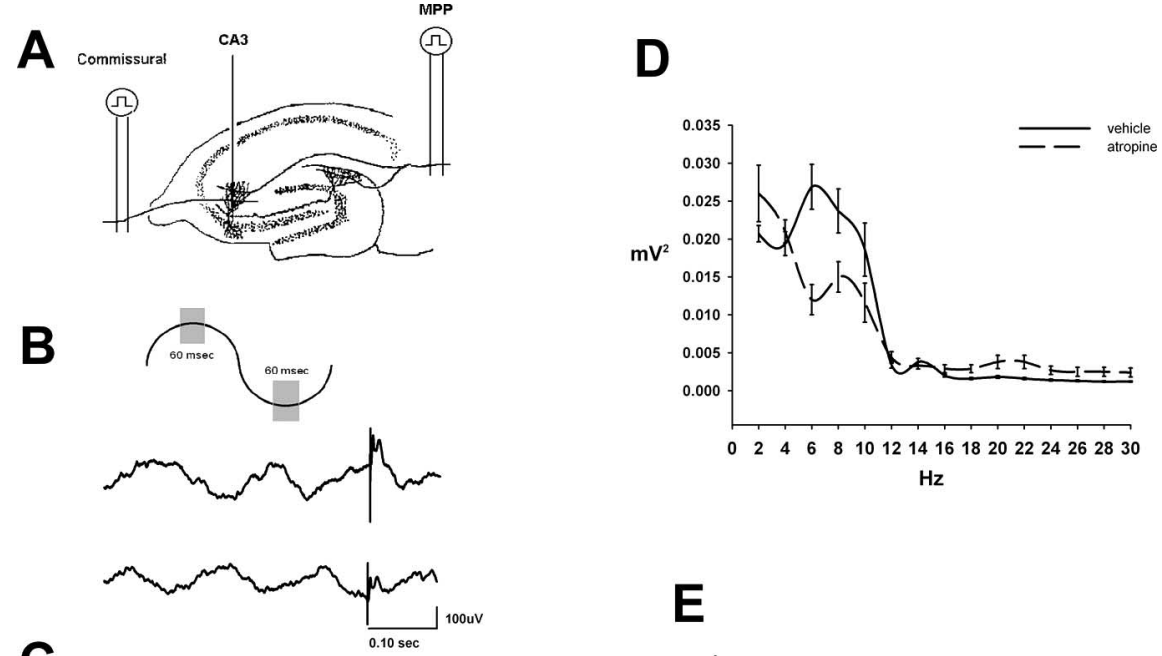

Recording ofEEG and field potentials in the CA3 region. $A$, Schematic diagram of the intact rodent preparation as used increase in the theta frequency of maximum power, and an attenuation of theta power among lower frequencies of the theta (he CA3 pyramidal cell region (all $p>0.05$, RM ANOVA). $\boldsymbol{E}$, Placement of CA3 recording electrodes for each subject as verified by histological analysis of cresyl-violet-stained sections, with electrode termination sites shown as circles, with termination sites determined by sclerosis, blood tracks, and cell displacement. $n=18$.

Theta modulation of CA3 afferent inputs habituates with reexposure to the novel environment

Our preliminary studies reported that the modulation of CA3 responses during theta rhythm was not observed in the animal's home cage or in familiar environments (Dieguez et al., 2004). We therefore determined if the modulation of CA3 synapses seen during the initial exploration of a novel environment also is observed during re-exposure to the same novel environment $2 \mathrm{~h}$ later. Because the modulation of CA3 afferent input is suggested to mediate both encoding and retrieval, the modulation of CA3 synaptic inputs observed during initial exploration also would be expected to occur during re-exposure, as recognition involves the retrieval of previously encoded information.

However, whereas cCA3-CA3 responses were reduced significantly on theta peaks during the initial exploration of the novel environment, this effect was absent after re-exposure to this same novel environment $2 \mathrm{~h}$ later, as evidenced by the absence of any alterations of cCA3-CA3 response magnitudes when evoked on 


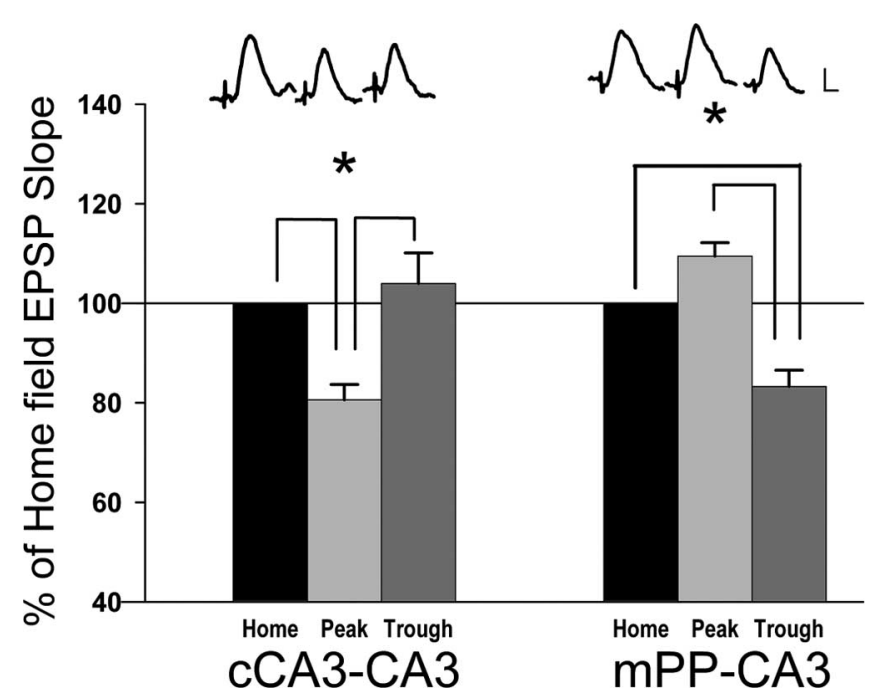

Figure 2. Differential effects of theta phase on $C A 3-C A 3$ and $m P P-C A 3$ synaptic responses during initial exploration of a novel environment. Left, Mean percent change ( $\pm S E M$ ) in cCA3CA3 field EPSP slopes ( $\mathrm{dV} / \mathrm{dt}$ ) compared with baseline synaptic responses collected in the home cage (defined as $100 \%$ response magnitude for each animal). A comparison of responses evoked during the initial exploration of a novel environment show cCA3-CA3 synaptic responses are reduced during $C A 3$ theta peaks when compared with both baseline responses collected in the home cage (home), and responses evoked on local theta troughs $\left({ }^{*} p<0.05\right.$, Tukey's test; $n=5)$. Right, Mean percent change ( \pm SEM) in $\mathrm{mPP}-$ CA3 synaptic responses relative to baseline responses collected in the home cage (defined as $100 \%$ of response amplitude) during the initial exploration of a novel environment. MPP-CA3 synaptic responses are reduced during local CA3 theta troughs when compared with both baseline responses collected in the home cage (home) and responses evoked on CA3 theta peaks ( ${ }^{*} p<0.05$, Tukey's test; $n=5$ ). Calibration: $0.5 \mathrm{mV}, 5 \mathrm{~ms}$.

theta peaks when compared with both baseline responses and trough cCA3-CA3 responses $\left(F_{(2,8)}=1.18 ; p>0.05, \mathrm{RM}\right.$ ANOVA; $n=5$ ) (Fig. $3 A$ ). Similarly, the reduction of mPP-CA3 responses on theta troughs also was absent after re-exposure to the same novel environment $2 \mathrm{~h}$ later $\left(F_{(2,8)}=0.01 ; p>0.05, \mathrm{RM}\right.$ ANOVA; $n=5$ ) (Fig. $3 B$ ). The modulation of CA3 synaptic responses in a novel environment and its subsequent habituation are summarized in Figure 3C. A comparison of theta rhythm, including total theta power, mean theta frequency, and percent theta power $(4-12 \mathrm{~Hz})$ within a $1-50 \mathrm{~Hz}$ band revealed no differences in theta during re-exposure when compared with theta generated during the initial period of exploration (mean frequency of maximal power, $5.4 \pm 0.9 \mathrm{~Hz}$ in the novel environment, and $6.2 \pm 0.8 \mathrm{~Hz}$ during re-exposure to the novel environment; $F_{(1,4)}=0.29, p>0.05$, RM ANOVA $n=5$; mean percent theta, $43.4 \pm 2 \%$ in novel; with re-exposure, $42.8 \pm 0.6 \% ; F_{(1,4)}=$ $0.045, p>0.05$, RM ANOVA, $n=5$ ).

It is possible that the attenuation of CA3 field EPSPs observed in novel environments, and its subsequent habituation, may be related to locomotor activity. Locomotor activity is associated with the generation of theta rhythm (Vanderwolf, 1969), and because overall activity may have been greater during the initial periods of exploration (Meeter et al., 2004), the habituation of CA3 response modulation could arise simply from reduced locomotion with familiarity, and a corresponding reduction in theta rhythm. To address this possibility, we monitored overall activity during both the period of initial exposure and the period of reexposure to the same novel environment. There was a nonsignificant reduction in overall activity when rats explored or reexplored the novel cage $2 \mathrm{~h}$ later $\left(77.0 \times 10^{5} \pm 11.3 \times 10^{5}\right.$ vs $73.2 \times 10^{5} \pm 15.1 \times 10^{5}$ pixels; $F_{(1,4)}=0.34, p=0.59, \mathrm{RM}$ ANOVA; $n=5)$.
Together, these data indicate that the initial exploration of a novel environment causes theta-phase and afferent-specific changes in CA3 synaptic transmission as predicted theoretically (Hasselmo et al., 2002; Kunec et al., 2005). Importantly, this modulation of CA3 synaptic responses is not observed with reexposure to the same novel environment $2 \mathrm{~h}$ later (Fig. $3 A-C$ ), indicating that the modulation of CA3 synaptic inputs during theta habituates with familiarity.

\section{Atropine blocks theta modulation of CA3 afferents}

The modulation of CA3 responses during local theta rhythm habituates with familiarity, suggesting that this effect reflects a process involved in learning about the novel environment (Meeter et al., 2004). A crucial factor in this effect is thought to be cholinergically mediated type 2 theta rhythm (Hasselmo et al., 2002; Kunec et al., 2005) a distinct form of theta rhythm associated with arousal and sensory processing (Sainsbury et al., 1987; Gray and McNaughton, 2003). If the modulation of CA3 synaptic inputs involves type 2 theta rhythm, then administration of atropine in a dose that eliminates type 2 theta would be expected to attenuate the modulation of CA3 synaptic responses during theta. Therefore, we investigated the contribution of type 2 theta rhythm to modulation of CA3 responses by administering atropine sulfate $(50 \mathrm{mg} / \mathrm{kg}) 1 \mathrm{~h}$ before the initial period of exploration of novel environments.

In these studies, tests of habituation were performed $48 \mathrm{~h}$ after drug administration and initial exploration to allow drugs to clear. We therefore first determined whether habituation could be observed at the $48 \mathrm{~h}$ time point in animals given only the vehicle. In animals receiving the water vehicle $60 \mathrm{~min}$ before exploration of a novel environment, a significant attenuation was observed (Fig. $4 A$ ), with a significant attenuation of cCA3-CA3 responses on theta peaks ( $79 \pm 4 \%$ of baseline on theta peaks vs $101 \pm 2 \%$ on theta troughs; $F_{(2,6)}=38.65 ; p<0.001, \mathrm{RM}$ ANOVA; $n=4)$ and mPP-CA3 responses on theta troughs ( $80 \pm$ $4 \%$ of baseline on theta troughs vs $101 \pm 1 \%$ on theta peaks; $F_{(2,6)}$ $=34.37 ; p<0.001 ; n=4)$. The habituation of the synaptic modulation effect, as reflected in the absence of modulation with re-exposure, was assessed by comparing the magnitude of responses evoked during the initial period of exploration with responses evoked during re-exposure. Habituation was evident after re-exposure to the environment $48 \mathrm{~h}$ later in both commissural $\left(F_{(2,6)}=19.06 ; p<0.05\right.$, RM ANOVA; $\left.n=4\right)$ and medial perforant path responses $\left(F_{(2,6)}=36.92 ; p<0.01 ; n=4\right)$ (Fig. $4 A$ ). No differences in overall activity were observed in vehicle-treated animals during the initial period of exposure and re-exposure to the environment $\left(F_{(1,4)}=0.48 ; p=0.52, \mathrm{RM}\right.$ ANOVA).

Administration of atropine sulfate $(50 \mathrm{mg} / \mathrm{kg})$ had no effect on the total power over a $1-50 \mathrm{~Hz}$ band, or percentage of power in the $4-12 \mathrm{~Hz}$ theta range ( $p>0.05 ; n=4)$. The power of lower theta frequencies ( 6 and $8 \mathrm{~Hz}$ ) was reduced by atropine, although this only approached significance (Fig. $1 D$ ) (RM ANOVA, $p=$ 0.11 for $6 \mathrm{~Hz}$ ). Thus, theta rhythm could still be observed locally in the CA3 region in the presence of atropine, consistent with previous studies indicating atropine, although effective in blocking type 2 theta, does not eliminate all theta rhythm (Gray and McNaughton, 2003; Leung and Shen, 2004). However, atropine blocked the modulation of CA3 responses typically observed during the initial exploration of a novel environment in both cCA3CA3 $\left(F_{(2,6)}=1.94\right.$; RM ANOVA, $\left.p=0.22\right)$ as well as mPP-CA3 responses $\left(F_{(2,6)}=0.27 ; p=0.77\right)$ as compared with home cage baseline responses (Fig. $4 B$ ). When compared with vehicle- 

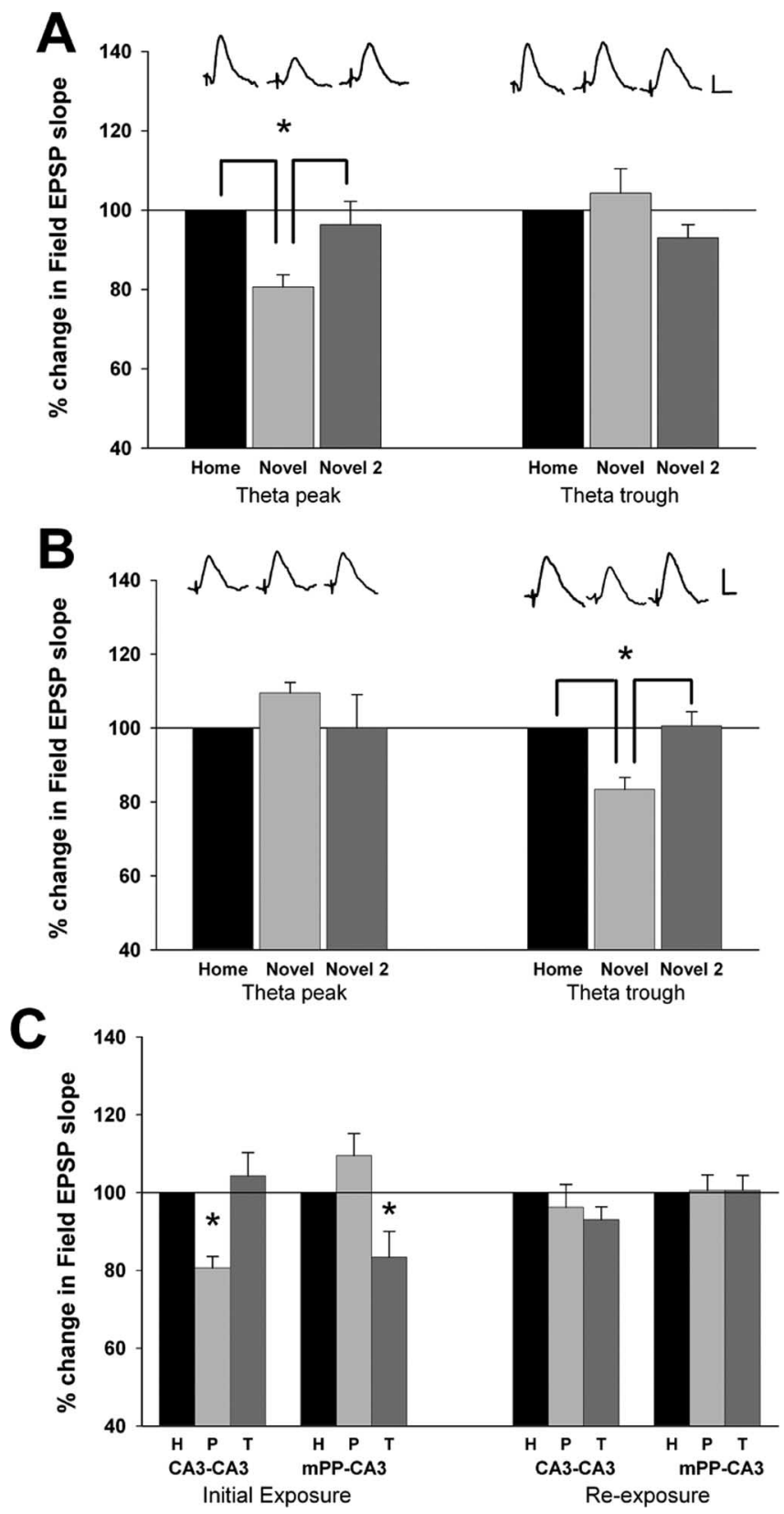

Figure 3. The modulation of $C C A 3-C A 3$ and $\mathrm{mPP}-\mathrm{CA} 3$ synaptic responses habituates with re-exposure to the novel environment. $\boldsymbol{A}$, Changes in c $C A 3-C A 3$ synaptic responses evoked on either theta peaks (left) or troughs (right) during the initial period of exploration, and reexposure to the same environment $2 \mathrm{~h}$ later. When compared with responses evoked in the home cage (home), cCA3-CA3 field EPSP slopes were attenuated on peaks of local theta generated during the initial exposure to a novel cage (novel). Re-exposure to the same cage $2 \mathrm{~h}$ later (novel 2) elicited exploration and theta, but CCA3-CA3 responses evoked on theta peaks were not altered during theta rhythm $\left({ }^{*} p<0.05\right.$, Tukey's test; $\left.n=5\right)$. $B$, Changes in mPP-CA3 synaptic responses evoked on theta peaks (left) and troughs (right) during initial exploration (novel) and re-exposure to the same environment $2 \mathrm{~h}$ later (novel 2). When compared with responses evoked in the home cage (home), mPP-CA3 field EPSP slopes were attenuated on local theta troughs generated during the initial exploration of a novel cage (novel). Re-exposure to the same cage $2 \mathrm{~h}$ later (novel 2) elicited exploration and theta, but MPP-CA3 responses evoked on local theta troughs were not altered during theta rhythm $\left({ }^{*} p<0.05\right.$, Tukey test; $n=5)$, indicating habituation of this effect. C, Summary of CA3 synaptic modulation and its subsequent habituation after re-exposure $2 \mathrm{~h}$ later to the once-novel environment. Shown are mean percent changes in $\mathrm{MPP}-\mathrm{CA} 3$ and $C \mathrm{CA} 3-\mathrm{CA} 3$ responses relative to baseline responses evoked in the home cage that were collected on either local CA3 theta peaks or theta troughs. Responses were collected during the initial 30 min period of exploration and the 30 min period of re-exposure to the novel environment $2 \mathrm{~h}$ later. During the initial period of exploration (initial exposure), cCA3-CA3 responses were attenuated on theta peaks $(P)$ relative to responses col- treated controls, atropine blocked both the reduction of cCA3CA3 synaptic responses on theta peaks $\left(F_{(1,6)}=15.02 ; p<0.01\right.$, ANOVA; $n=4)$ and the reduction of mPP-CA3 responses on theta troughs $\left(F_{(1,6)}=26.87 ; p<0.01\right.$, ANOVA; $\left.n=4\right)$. In addition, measures of overall activity revealed a significant increase in activity during the $30 \mathrm{~min}$ period of exploration in animals treated with atropine compared with the vehicle $\left(F_{(1,7)}=\right.$ $10.29 ; p<0.05$, ANOVA; $n=8$ ). Because a $50 \mathrm{mg} / \mathrm{kg}$ dose of atropine blocks type 2 theta, but does not eliminate all theta (Vanderwolf and Leung, 1983; Gray and McNaughton, 2003), the remaining, presumably type 1 , theta rhythm apparently does not modulate CA3 synaptic responses. Together, this suggests the involvement of muscarinic receptors and atropine-sensitive (type 2) theta rhythm in the modulation of CA3 synaptic responses.

We also examined the effect of atropine administered during initial exploration on habituation that is observed $48 \mathrm{~h}$ later. If the modulation of CA3 afferents by type 2 theta rhythm contributes to learning, as reflected in the habituation of CA3 synaptic modulation, atropine also would be expected to eliminate the habituation that follows re-exposure to the formerly novel environment $48 \mathrm{~h}$ later. In atropine treated animals, the habituation of synaptic modulation typically observed with re-exposure to the environment was not observed. Instead, re-exposure to the same novel environment $48 \mathrm{~h}$ after exploration under atropine elicited a significant modulation of cCA3-CA3 and mPP-CA3 synaptic responses during theta (Fig. $4 B$ ), as indicated by significant decreases in both cCA3-CA3 responses on theta peaks ( $85 \pm 3 \%$ of baseline on theta peaks vs $102 \pm 1 \%$ on theta troughs; $F_{(2,6)}=$ $30.1 ; p<0.001$, RM ANOVA; $n=4)$ and mPP-CA3 responses evoked on theta troughs ( $85 \pm 4 \%$ of baseline on theta troughs vs $104 \pm 1 \%$ on theta peaks; $\left.F_{(2,6)}=14.0 ; p<0.01 ; n=4\right)$ compared with habituation that is observed in vehicle-treated controls (Fig. 4, compare $A, B$ ). This is unusual in that modulation of CA3 synaptic responses typically is seen only during the initial exploration of a novel environment. Thus, re-exposure to the same novel environment $48 \mathrm{~h}$ after initial exploration with atropine elicited a modulation of CA3 synaptic responses during theta, as though the environment were novel and explored for the first time.

Although increased activity during initial exploration was observed with atropine when compared with vehicle, there were no significant differences in overall activity during the initial period of exploration and the period of re-exposure in atropine-treated animals $\left(F_{(1,3)}=3.10 ; p>0.05\right.$, RM ANOVA; $\left.n=4\right)$. This suggests that the block of CA3 synaptic modulation by atropine was not related to increased ambulation, and a possible "dilution" of type 2 theta by type 1 theta with increased activity. Thus, atropine blocked both synaptic modulation with novelty, as well as the habituation of this modulatory effect normally observed with re-exposure to the once-novel environment. The appearance of modulation with re-exposure may have resulted from a block of the modulatory process itself, which requires muscarinic receptors, and possibly type 2 theta rhythm.

\section{$\leftarrow$}

lected on theta troughs ( $\mathrm{T}$ ) or baseline responses collected in the home cage $(H)$. Conversely, mPP-CA3 responses were attenuated significantly on theta troughs ( $\mathrm{T}$ ) compared with responses evoked on peaks $(\mathrm{P})$ and baseline responses $(\mathrm{H})$. However, when re-exposed to the same novel environment $2 \mathrm{~h}$ later (re-exposure), neither mPP-CA3 nor cCA3 responses were altered by theta rhythm elicited during exploration $\left[{ }^{*} p<0.05\right.$ when compared with both home responses and troughs (CCA3) or peak (mPP) responses, Tukey's test; $n=5$ ]. Calibration: $A, B, 0.5 \mathrm{mV}, 5 \mathrm{~ms}$. 


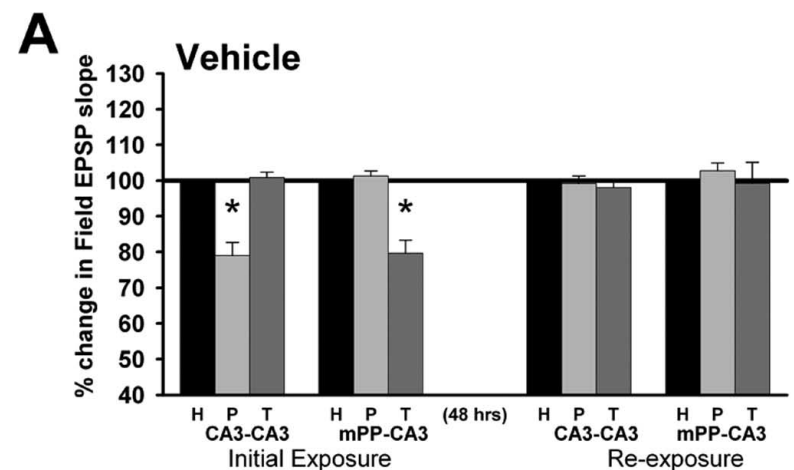

B
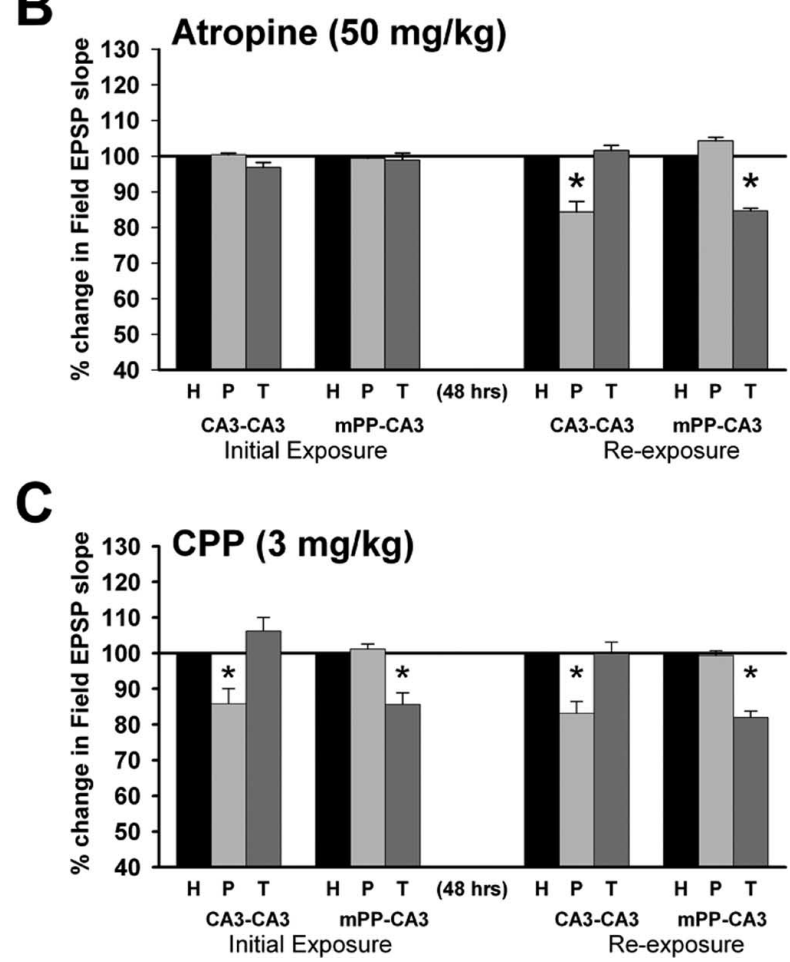

Figure 4. The effects of atropine and NMDA receptor antagonists on the modulation of CA3 synaptic responses and habituation. Shown are changes in $\mathrm{MPP}$ - and $\mathrm{C} C \mathrm{C} 3-\mathrm{CA} 3$ response magnitudes relative to home cage baseline responses $(\mathrm{H} ; 100 \%)$ when elicited on either $\mathrm{CA} 3$ theta peaks $(P)$ or troughs $(T)$, presented as in Figure $3 C$. Responses were collected during both the initial 30 min period of exploration after administration of drug or vehicle, and during the 30 min period of re-exposure to the same, unaltered novel environment $48 \mathrm{hlater}$. $A$, Sixty minutes after administration of the water vehicle, modulation of $C A 3$ responses was observed during the initial exploration of the novel environment, with an attenuation of $C$ CA3-CA3 responses observed on theta peaks, and an attenuation of $\mathrm{MPP}-\mathrm{CA} 3$ responses observed on theta troughs $\left({ }^{*} p<0.05\right.$, Tukey's test; $\left.n=4\right)$. Re-exposure to the same environment $48 \mathrm{~h}$ later elicited theta rhythm, but neither $\mathrm{C} \mathrm{CA} 3-\mathrm{CA} 3$ nor mPP-CA3 responses were altered significantly by theta phases, indicating habituation of this effect. $\boldsymbol{B}$, During the initial period of exploration (initial exploration) and $60 \mathrm{~min}$ after administration of atropine sulfate in a dose known to block type 2 theta rhythm $(50 \mathrm{mg} / \mathrm{kg})$, modulation of CA3 synaptic responses that typically is seen during the initial period of exploration was not observed. However, after re-exposure $48 \mathrm{~h}$ after atropine administration and initial exploration, modulation of $C A 3$ responses was then observed, with significant attenuation of $C$ CA3-CA3 responses and $\mathrm{mPP}-\mathrm{CA} 3$ responses on theta peaks and troughs, respectively ( ${ }^{*} p<0.05$, Tukey's test; $\left.n=4\right)$. C, After administration of $3 \mathrm{mg} / \mathrm{kg}$ CPP 90 min before initial exploration, the usual modulation of CA3 synaptic responses during theta rhythm was still observed, with a significant attenuation of both $c$ CA3-CA3 responses on theta peaks and mPP-CA3 responses on theta troughs $\left({ }^{*} p<0.05\right.$, Tukey's test; $n=5$ ). However, upon re-exposure to the same environment $48 \mathrm{~h}$ later, habituation was blocked, with reexposure again eliciting a modulation of $\mathrm{CA} 3$ responses, and significant attenuation of $C \mathrm{CA} 3-$ CA3 and $\mathrm{mPP}-\mathrm{CA} 3$ responses on theta peaks and troughs, respectively $\left({ }^{*} p<0.05\right.$, Tukey's test; $n=5$ ). The modulation of CA3 responses seen with re-exposure also did not differ significantly from the magnitude of modulation observed during the initial period of exploration in the same animals (Tukey's test, $p>0.05 ; n=5$ ).

\section{NMDA receptor antagonists block habituation}

In models in which encoding and retrieval involve theta rhythm, synaptic plasticity in CA3 afferents is suggested to mediate the encoding of new information (Hasselmo et al., 1995, 2002; Wyble et al., 2000; Kunec et al., 2005). The mechanism suggested to mediate this plasticity is LTP (Hasselmo et al., 1995; Kunec et al., 2005). Because LTP is induced preferentially on local theta peaks (Pavlides et al., 1988; Huerta and Lisman, 1995; Orr et al., 2001; Hyman et al., 2003), enhanced perforant path input during theta peaks is suggested to mediate encoding by directing LTP induction within the CA3 region (Kunec et al., 2005). If LTP contributes to the encoding of new information during modulation of CA3 inputs with theta rhythm, then administration of an NMDA receptor antagonist in a dose that blocks either LTP induction or afferent modulation also would be expected to block the habituation of CA3 synaptic modulation typically observed with reexposure to the now familiar environment.

We investigated the contribution of NMDA receptors to the theta phase modulation and its subsequent habituation using the NMDA receptor antagonist CPP. Previously, we showed that $\mathrm{CPP}$, at a dose of 3 and $10 \mathrm{mg} / \mathrm{kg}$, blocks LTP induction at cCA3CA3 synapses in anesthetized animals (Hernandez et al., 1994). This antagonist is also effective in blocking mPP-CA3 LTP in vivo (Do et al., 2002). However, previous studies indicate higher doses of NMDA receptor antagonists reduced theta total power, in line with reports indicating the possible involvement of NMDA receptors in both type 1 (Buzsaki, 2002) and type 2 theta rhythm (Pitkanen et al., 1995; Leung and Shen, 2004). Such effects of CPP on theta rhythm presents a potential confound, as the effects of CPP on theta rhythm may alter the modulatory process itself (as suggested for atropine) rather than blocking NMDAR-mediated synaptic plasticity hypothesized to mediate encoding on theta peaks (Kunec et al., 2005). We therefore used a lower dose of CPP $(3 \mathrm{mg} / \mathrm{kg}$ ) found effective in blocking cCA3-CA3 LTP in vivo (Hernandez et al., 1994). When compared with vehicle-treated controls, the $3 \mathrm{mg} / \mathrm{kg}$ dose of CPP did not alter significantly total power $(1-50 \mathrm{~Hz})$ in a novel environment (vehicle, $0.052 \pm 0.02$ $\mathrm{mV}^{2}$ in novel environments, $n=4 ; 3 \mathrm{mg} / \mathrm{kg} \mathrm{CPP}, 0.038 \pm 0.02$ $\left.\mathrm{mV}^{2}, n=5\right)$, percent theta power $(4-12 \mathrm{~Hz})$ over a $1-50 \mathrm{~Hz}$ band (percent theta vehicle, $46 \pm 4 \%$; percent theta with CPP, $50 \pm$ $4 \%$ ), nor the frequency of maximal power (maximal frequency, $6.3 \pm 0.75 \mathrm{~Hz}$ for vehicle-treated controls, $6.8 \pm 0.25 \mathrm{~Hz}$ for 3 $\mathrm{mg} / \mathrm{kg}$ CPP; all $p>0.05$, one-way ANOVA).

When administered $90 \mathrm{~min}$ before the initial exploration of the novel environment, $3 \mathrm{mg} / \mathrm{kg}$ of CPP did not alter modulation of CA3 synaptic responses with theta rhythm (Fig. 4C). A significant reduction in cCA3-CA3 responses was observed on theta peaks ( $86 \pm 3 \%$ of baseline on theta peaks vs $106 \pm 4 \%$ on theta troughs; $F_{(2,8)}=11.12, p<0.01$, RM ANOVA; $\left.n=5\right)$ and a reduction of $\mathrm{mPP}-\mathrm{CA} 3$ responses was observed on theta troughs $(86 \pm 2 \%$ of baseline on theta troughs vs $101 \pm 1 \%$ on theta peaks; $F_{(2,8)}=58.58, p<0.001 ; n=5$ ) (Fig. $4 C$ ). Moreover, the magnitude of attenuation of synaptic responses during initial exploration with CPP did not differ significantly from the that observed in vehicle-treated controls for both cCA3-CA3 responses $\left(F_{(1,7)}=1.95 ; p>0.05\right.$, ANOVA; $\left.n=9\right)$ and mPP-CA3 responses $\left(F_{(1,7)}=2.37 ; p>0.05\right.$, ANOVA; $\left.n=9\right)$ (Fig. 4 , compare $A, C)$.

As in our studies with atropine, tests of habituation were given $48 \mathrm{~h}$ after the initial exposure to allow for clearance of CPP. When animals treated with CPP were re-exposed to the novel cage $48 \mathrm{~h}$ later, the habituation of CA3 synaptic modulation typically seen after re-exposure to the same environment in vehicle-treated an- 
imals was absent. Instead, as was observed with atropine, reexposure to the same novel environment $48 \mathrm{~h}$ after CPP administration elicited a modulation of CA3 synaptic responses during theta rhythm (Fig. 4C). This was indicated by a significant reduction of cCA3-CA 3 responses on theta peaks ( $83 \pm 3 \%$ of baseline on theta peaks vs $100 \pm 3 \%$ on theta troughs; $F_{(2,8)}=17.1 ; p=$ 0.01 , RM ANOVA; $n=5$ ) and a significant reduction of medial perforant path-CA3 responses on theta troughs $(82 \pm 2 \%$ of baseline on theta troughs vs $99 \pm 2 \%$ on theta peaks; $F_{(2,8)}=$ 57.11; $p<0.001 ; n=5)$. Comparison with vehicle-treated controls revealed a significant attenuation of response magnitudes during the period of re-exposure in both cCA3-CA3 responses $\left(F_{(1,7)}=21.56 ; p<0.01, n=5\right.$; ANOVA, $\left.n=9\right)$ and mPP-CA3 responses $\left(F_{(1,7)}=39.36 ; p<0.001 ; n=9\right)$. Moreover, the modulation seen with re-exposure did not differ significantly from modulation during the initial period of exploration with CPP for both cCA3-CA3 responses $\left(F_{(1,4)}=3.0 ; p>0.05\right.$, RM ANOVA; $n=5)$ and mPP-CA3 responses $\left(F_{(1,4)}=3.0 ; p>0.05, \mathrm{RM}\right.$ ANOVA; $n=5)$. Thus, habituation was not observed with reexposure to the novel environment when $3 \mathrm{mg} / \mathrm{kg}$ CPP was present during the initial period of exploration, and modulation of intrinsic and extrinsic CA3 synaptic responses was again observed after re-exposure to the environment (Fig. 4, compare A, $C)$. As was observed with the water vehicle, there were no significant differences in overall activity among animals treated with CPP or vehicle during the initial period of exploration $\left(F_{(1,7)}=\right.$ $0.57 ; p=0.82$, ANOVA; $n=10$ ). Thus, CPP, in a dose reported previously to block LTP in vivo, also blocked habituation of the modulation of CA3 synaptic responses that normally is seen with re-exposure. Importantly, this block of habituation was seen although CPP appeared to have no effect on the modulation of CA3 synaptic responses during the initial exploration of the novel environment.

We also determined whether the $3 \mathrm{mg} / \mathrm{kg}$ dose of CPP used here is sufficient to block LTP induced in these afferent projections by high-frequency stimulation of cCA3-CA3 or mPP-CA3 afferents in the same animals. LTP was induced using four $0.5 \mathrm{~s}$, $100 \mathrm{~Hz}$ trains delivered to either the cCA3 region or the medial perforant path electrode $90 \mathrm{~min}$ after administration of $3 \mathrm{mg} / \mathrm{kg}$ CPP or the water vehicle. When compared with vehicle-treated controls, the $3 \mathrm{mg} / \mathrm{kg}$ dose blocked completely LTP induction at medial perforant path-CA3 synapses when measured 25-30 min post-tetanus (percent of baseline mPP-CA3 field EPSP slopes with LTP induced with vehicle, $190 \pm 49 \%, n=3$; with $3 \mathrm{mg} / \mathrm{kg}$ CPP, $97 \pm 3 \%, n=3 ; F_{(1,4)}=11.21 ; p<0.05$, ANOVA) (Fig. $5 A$ ). However, the $3 \mathrm{mg} / \mathrm{kg}$ dose of CPP attenuated LTP magnitude at CA3-CA3 synapses, but this was not significant (percent of baseline cCA3-CA3 field EPSP slopes for LTP induced with vehicle, $176 \pm 18 \%, n=4 ; 3 \mathrm{mg} / \mathrm{kg} \mathrm{CPP}, 144 \pm 26 \%, n=4 ; F_{(1,6)}=0.72$; $p>0.05$, ANOVA) (Fig. $5 B$ ). In addition, a potentiation of cCA3CA3 responses $>50 \%$ was seen in two of four animals. Thus, whereas $3 \mathrm{mg} / \mathrm{kg}$ of CPP blocks mPP-CA3 LTP induction, this same dose only attenuated cCA3-CA3 LTP induction in behaving animals.

Together, these data indicate that administration of an NMDAR antagonist before initial exploration of a novel environment, in a dose that blocks medial perforant path LTP, blocks the habituation of CA3 synaptic modulation usually seen with reexploration of a novel environment. Importantly, unlike atropine, CPP blocked habituation without altering the modulation of CA3 synaptic responses seen during the initial period of exploring the novel environment. Thus, it is unlikely that CPP blocked habituation by altering theta rhythm or the modulatory
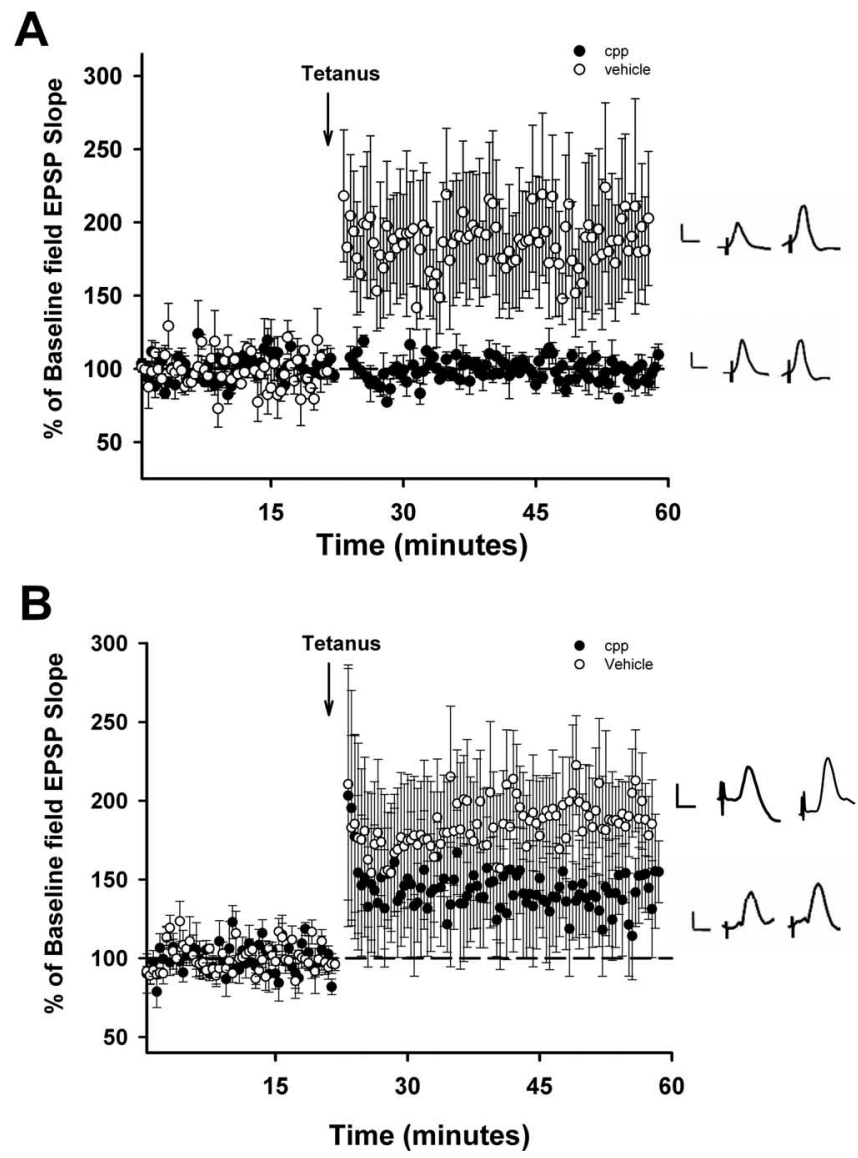

Figure 5. Induction of LTP in medial perforant path-CA3 synapses, but not CCA3-CA3 synapses, is blocked by $3 \mathrm{mg} / \mathrm{kg}$ of the NMDA receptor antagonist (PP. LTP was induced by high frequency stimulation (four $0.5 \mathrm{~s} 100 \mathrm{~Hz}$ trains) of mPP fibers in the angular bundle or commissural/associational CA3 fibers in the contralateral CA3 region while the animal was awake in its home cage. $A$, Tetanization of the mPP fibers 90 min after intraperitoneal administration of the water vehicle $(\bigcirc)$ resulted in LTP of mPP-CA3 synaptic responses ( $190 \pm 49 \%$ of baseline; $n=$ 3). LTP of mPP-CA3 responses was blocked completely by $3 \mathrm{mg} / \mathrm{kg}$ of CPP ( $)$ when administered 90 min before tetanization ( $97 \pm 3 \%$ of baseline; $n=3$ ). $\boldsymbol{B}$, Tetanization of the contralateral CA3 region (CCA3) 90 min after administration of the water vehicle $(\bigcirc)$ induced LTP of CCA3-CA3 responses $(176 \pm 18 \%, n=4)$, Administration of $3 \mathrm{mg} / \mathrm{kg}$ CPP reduced LTP magnitude $(\mathbf{)})$, but not significantly $(144 \pm 26 \% ; n=4)$, with a potentiation of field EPSP slopes $>50 \%$ observed in $2 / 4$ animals. Calibration: $A, B, 0.5 \mathrm{mV}, 5 \mathrm{~ms}$.

process itself. Rather, some other NMDAR-dependent process appears necessary for the habituation of this modulatory effect.

\section{Discussion}

We report here that, during the initial exploration of novel environments, CA3 synaptic responses from distinct CA3 afferents are differentially modulated during theta rhythm. This finding, in addition to other behavioral studies (Rogers and Kesner, 2003; Hunsaker et al., 2007), supports the predictions of specific models of hippocampal operation (Hasselmo et al., 2002; Kunec et al., 2005). In these models, at the peak of local CA3 theta rhythm, extrinsic inputs from the entorhinal cortex via the perforant path to the $\mathrm{CA} 3$ region are favored because of an attenuation of intrinsic CA3-CA3 transmission. This could allow for extrinsic inputs from the entorhinal afferents to dominate CA3 input during encoding, while simultaneously minimizing interactions among CA3 neurons and interference from previously encoded associations among strengthened CA3-CA3 synapses (Hasselmo et al., 2002; Kunec et al., 2005). Conversely, during theta troughs, intrinsic CA3-CA3 inputs are favored because of the attenuation of 
extrinsic perforant path-CA3 transmission, maximizing activity among intrinsic, recurrent CA3-CA3 inputs, and minimizing interference from extrinsic inputs, favoring intrinsic CA3-CA3 activity, pattern completion and retrieval (Hasselmo et al., 2002).

\section{CA3 synaptic modulation habituates with familiarity}

The modulation of CA3 responses during theta rhythm was absent when animals were re-exposed to the formerly novel environment, suggesting that modulation of CA3 synaptic responses habituates with familiarity and, thus, reflect a process related to learning (Thiel et al., 1998). Thus the modulation of CA3 afferent input on theta phase appears to be operative primarily during periods of novelty, and, presumably encoding of new information. Similarly, we reported previously that LTP at the perforant path-dentate synapse displays enhanced magnitude and longevity when induced in a novel environment, an effect that also habituates once animals become familiar with the environment (Davis et al., 2004). Together, these findings support the view that the degree of novelty within an environment elicits a "mode" of hippocampal operation during which pattern separation (Guzowski et al., 2004; Lee and Kesner, 2004; Lee et al., 2004; Leutgeb et al., 2004; Vazdarjanova and Guzowski, 2004), synaptic plasticity (Davis et al., 2004; Meeter et al., 2004), and encoding are favored (Davis et al., 2004). Thus, the modulation of CA3 synaptic responses during theta rhythm is associated with novelty and, thus, appears to be operative primarily during learning and, thus, may reflect encoding processes within the hippocampus.

\section{The modulation of CA3 afferents involves atropine-sensitive theta rhythm}

If the modulation of CA3 input during theta rhythm reflects a process involved in the encoding of memory, then blocking this process should also block learning and, thus, would be reflected by the absence of habituation normally observed after reexposure. This was observed here, where the cholinergic antagonist atropine sulfate, given before the initial exploration of a novel environment, blocked the modulation of CA3 synaptic input usually observed when animals explore a novel environment for the first time. However, re-exposure to the same environment explored in the presence of atropine elicited modulation of CA3 synaptic inputs, as though the environment were novel and explored for the first time. This indicates that atropine not only blocked the modulation of CA3 responses, but elicited synaptic modulation upon re-exposure to same environment $48 \mathrm{~h}$ later. Thus atropine, by blocking CA3 modulation during theta rhythm, also blocked encoding, resulting in a modulation of CA3 synaptic responses $48 \mathrm{~h}$ later, as though the environment were "novel" and explored for the first time. Importantly, equivalent doses of atropine are amnestic, and impair performance on tasks dependent on hippocampal function (Singh et al., 1974; Hagan et al., 1986).

The modulation of CA3 inputs observed in novel environments was blocked by atropine at a dose that blocks type 2 theta rhythm (Fox et al., 1983). However, theta rhythm was still observed in the CA3 region in the presence of atropine. Thus, the modulation of CA3 synaptic inputs appears to involve atropinesensitive (type 2) theta rhythm, rather than atropine-insensitive type 1 theta rhythm. Thus, the modulation of CA3 afferent input involves type 2 theta rhythm, associated with stimulus processing, arousal, and associative learning (Sainsbury et al., 1987; Seidenbecher et al., 2003). Type 2 theta rhythm also is reported to habituate with repeated stimuli (Irmis et al., 1970; Whishaw and Vanderwolf, 1973; O'Keefe and Nadel, 1978). Thus, the habitua- tion of CA3 afferent modulation observed here may reflect the habituation of atropine-sensitive (type 2) theta rhythm with reexploration. However, this was not discernable in measures of EEG, as mean theta frequency, frequency of maximal power, and percent theta did not differ significantly among novel and familiar environments (all $p$ values $>0.05$ ).

\section{NMDAR antagonists block habituation without altering the modulation during theta rhythm}

If LTP occurring during CA3 theta peaks contributes to encoding, as postulated by Kunec et al. (2005), blocking LTP induction with an NMDA receptor antagonist also would be expected to prevent learning. This would be reflected in the absence of habituation typically seen with re-exposure. In these studies, a dose of the NMDAR antagonist CPP effective in blocking medial perforant path-CA3 LTP induction had no effect on the modulation of CA3 afferents during theta generated during initial exploration. However, when tested 48 h later, a modulation of CA3 inputs was again observed, and the habituation of theta modulation normally seen with re-exposure to the environment was absent. Thus, the modulation of CA3 inputs with initial exposure was unaffected by CPP, but, as seen with atropine, re-exposure to the same novel environment again elicited a modulation of CA3 inputs during theta, as if the environment were novel, and animals were exploring the environment for the first time. Thus, CPP, in a dose that effectively blocked mPP-CA3 LTP induction, blocked the habituation of CA3 synaptic modulation normally observed after re-exposure.

Importantly, CPP blocked habituation of theta modulation without altering theta modulation of CA3 inputs. In contrast, atropine blocked both the modulation of CA3 responses during initial exploration, and the habituation usually observed with re-exposure to the now-familiar environment. This suggests atropine prevented habituation by blocking the CA3 modulatory process itself, possibly by blocking type 2 theta, whereas CPP blocked habituation via blocking NMDA receptor-dependent processes unrelated to theta or the modulation of CA3 afferent inputs. One possibility is that CPP blocked NMDAR-dependent LTP thought necessary for encoding (Hasselmo et al., 2002; Kunec et al., 2005). This is supported by the present findings indicating that CPP blocked both medial perforant path-CA3 LTP and the habituation of theta modulation usually observed with re-exposure. Interestingly, although LTP at CA3-CA3 synapses was only attenuated by CPP, this dose effectively blocked LTP at medial perforant path-CA3 synapses, offering support for the specific theoretical assertion that LTP induced in extrinsic (perforant path) CA3 afferents during local theta peaks is critical for encoding (Hasselmo et al., 2002; Kunec et al., 2005).

\section{Retrieval during theta may "append" or "update" stored information}

Although the modulation of CA3 afferents by theta phase observed in novel environments suggests a role for this effect in encoding, retrieval also is suggested to involve the modulation of afferents during theta rhythm (Hasselmo et al., 2002; Kunec et al., 2005). However, our findings indicate that CA3 responses are not modulated during retrieval, as modulation was absent when animals were re-exposed to the novel environment, when retrieval would be expected. However, this does not rule out a role for theta in retrieval processes. It remains possible that the synaptic dynamics necessary for retrieval on theta troughs may occur elsewhere, such as the CA1 region, the entorhinal cortex (EC), or among EC-CA1 or EC-EC projections (Hasselmo, 2005). 
It is also possible that the dominance of CA3-CA3 synapses on theta troughs may reflect a retrieval process, albeit one that occurs only in conjunction with encoding of new information. Such a process could integrate encoding and retrieval, allowing an "appending" or "updating" of older information with the encoding of new, related information (Hasselmo et al., 2002; Kunec et al., 2005). This might explain some aspects of the "reconsolidation" effect observed after recall of associative memory tasks (Przybyslawski and Sara, 1997; Debiec et al., 2002; Tronel et al., 2005; Morris et al., 2006; Artinian et al., 2007). With reconsolidation, previously learned tasks, when recalled, once again become labile and sensitive to disruption by protein synthesis inhibition (Przybyslawski and Sara, 1997; Debiec et al., 2002; Tronel et al., 2005; Morris et al., 2006). Perhaps reconsolidation may reflect an encoding process that "appends" or "updates" previously acquired information when novel, task-relevant information is present during recall, a process that might be mediated by the theta modulation observed here (Kunec et al., 2005; Tronel et al., 2005; Morris et al., 2006; Rossato et al., 2006). Previous studies support this interpretation, indicating the sensitivity of recalled hippocampal tasks to disruption is most apparent when additional, novel stimuli are present during recall (Biedenkapp and Rudy, 2004; Tronel et al., 2005; Morris et al., 2006; Rossato et al., 2006).

These data indicate that atropine-sensitive theta rhythm influences the magnitude of intrinsic and extrinsic CA3 afferents in a phase-specific manner. This effect habituates with familiarity, and NMDA receptors are required for this effect, suggesting a learning process that involves both type 2 theta rhythm and NMDA receptor activation. Together, these findings offer support for models of Hasselmo et al. $(1995,2002)$ implicating theta phase modulation of CA3 afferents, together with LTP, as a process that could parcel information storage and retrieval (Kunec et al., 2005). This process also may mediate recall with new encoding, allowing for the updating or integration, and possibly the reconsolidation of information stored previously in the hippocampal CA3-CA3 network.

\section{References}

Abraham WC, Robins A (2005) Memory retention-the synaptic stability versus plasticity dilemma. Trends Neurosci 28:73-78.

Artinian J, De Jaeger X, Fellini L, de Saint Blanquat P, Roullet P (2007) Reactivation with a simple exposure to the experimental environment is sufficient to induce reconsolidation requiring protein synthesis in the hippocampal CA3 region in mice. Hippocampus 17:181-191.

Biendenkapp JC, Rudy JW (2004) Context memories and reactivation: constraints on the reconsolidation hypothesis. Behav Neurosci 118:956-964.

Bland BH, Konopacki J, Dyck R (2005) Heterogeneity among hippocampal pyramidal neurons revealed by their relation to theta-band oscillation and synchrony. Exp Neurol 195:458-474.

Brankack J, Stewart M, Fox SE (1993) Current source density analysis of the hippocampal theta rhythm: associated sustained potentials and candidate synaptic generators. Brain Res 615:310-327.

Buzsaki G (1986) Generation of hippocampal EEG patterns. In: The hippocampus, Vol III (Isaaacson RL, Pribram K, eds). New York: Plenum.

Buzsaki G (2002) Theta oscillations in the hippocampus. Neuron 33:325-340.

Csicsvari J, Hirase H, Czurko A, Mamiya A, Buzsaki G (1999) Fast network oscillations in the hippocampal CA1 region of the behaving rat. J Neurosci 19:RC20.

Davis CD, Jones FL, Derrick BE (2004) Novel environments enhance the induction and maintenance of long-term potentiation in the dentate gyrus. J Neurosci 24:6497-6506.

Debiec J, LeDoux JE, Nader K (2002) Cellular and systems reconsolidation in the hippocampus. Neuron 36:527-538.

Derrick BE, Martinez Jr JL (1994) Frequency-dependent associative longterm potentiation at the hippocampal mossy fiber-CA3 synapse. Proc Natl Acad Sci USA 91:10290-10294.
Dieguez Jr D, Kosub K, Derrick BE (2004) Novelty exploration elicits reversible, theta phase- and synapse-specific changes in CA3 synaptic responses. Soc Neurosci Abstr 30:974.2.

Do VH, Martinez CO, Martinez Jr JL, Derrick BE (2002) Long-term potentiation in direct perforant path projections to the hippocampal CA3 region in vivo. J Neurophysiol 87:669-678.

Fox SE, Wolfson S, Ranck Jr JB (1983) Hippocampal rhythmical slow activity. In: The neurobiology of the hippocampus (Seifert W, ed). London: Academic.

Fox SE, Wolfson S, Ranck Jr JB (1986) Hippocampal theta rhythm and the firing of neurons in walking and urethane anesthetized rats. Exp Brain Res 62:495-508.

Gray JA (1971) Medial septal lesions, hippocampal theta rhythm and the control of vibrissal movement in the freely moving rat. Electroencephalogr Clin Neurophysiol 30:189-197.

Gray JA, McNaughton N (2003) The neuropsychology of anxiety: an enquiry into the function of the septo-hippocampal system. London: Oxford UP.

Grossberg S (1987) Competitive learning: from interactive activation to adaptive resonance. Cogn Sci 11:23-63.

Guzowski JF, Knierim JJ, Moser EI (2004) Ensemble dynamics of hippocampal regions CA3 and CA1. Neuron 44:581-584.

Hagan JJ, Tweedie F, Morris RGM (1986) Lack of task specificity and absence of posttraining effects of atropine on learning. Behav Neurosci 100:483-493.

Hasselmo ME (2005) What is the function of hippocampal theta rhythm?Linking behavioral data to phasic properties of field polential and unit recording data. Hippocampus 15:936-949.

Hasselmo ME, Bower JM (1992) Cholinergic suppression specific to intrinsic not afferent fiber synapses in rat piriform (olfactory) cortex. J Neurophysiol 67:1222-1229.

Hasselmo ME, Schnell E, Barkai E (1995) Dynamics of learning and recall at excitatory recurrent synapses and cholinergic modulation in rat hippocampal region CA3. J Neurosci 15:5249-5262.

Hasselmo ME, Bodelon C, Wyble BP (2002) A proposed function for hippocampal theta rhythm: separate phases of encoding and retrieval enhance reversal of prior learning. Neural Comput 14:793-817.

Hernandez RV, Derrick BE, Rodriguez WA, Martinez Jr JL (1994) (+)CPP, an NMDA receptor antagonist, blocks the induction of commissural-CA3 LTP in the anesthetized rat. Brain Res 656:215-219.

Hertz JA, Krogh AS, Palmer RG (1991) Introduction to the theory of neural computation. Redwood City, CA: Addison-Wesley.

Huerta PT, Lisman JE (1995) Bidirectional synaptic plasticity induced by a single burst during cholinergic theta oscillation in $\mathrm{CAl}$ in vitro. Neuron 15:1053-1063.

Hunsaker MR, Rogers JL, Kesner RP (2007) Behavioral characterization of a transection of dorsal CA3 subcortical efferents: comparison of scopolamine and physostigmine infusions into the dorsal CA3. Neurobiol Learn Mem 88:127-136.

Hyman JM, Wyble BP, Goyal V, Rossi CA, Hasselmo ME (2003) Stimulation in hippocampal region CA1 in behaving rats yields LTP when delivered to the peak of theta and LTD when delivered to the trough. J Neurosci 23:11725-11731.

Irmis F, Radil-Weiss T, Lat J, Krekule I (1970) Inter-individual differences in hippocampal theta activity during habituation. Electroencephalogr. Clin Neurophysiol 28:24-31.

Kamondi A, Acsady L, Wang XJ, Buzsaki G (1998) Theta oscillations in somata and dendrites of hippocampal pyramidal cells in vivo: activity dependent phase-precession of action potentials. Hippocampus 8:244-261.

Keppel G, Zedeck S (1991) Data analysis for research designs, pp. 474. Upper Saddle River, NJ: Prentice-Hall.

Kocsis B, Bragin A, Buzsaki G (1999) Interdependence of multiple theta generators in the hippocampus: a partial coherence analysis. J Neurosci 19:6200-6212.

Kunec S, Hasselmo ME, Kopell N (2005) Encoding and retrieval in the CA3 region of the hippocampus: a model of theta-phase separation. J Neurophysiol 94:70-82.

Lee I, Kesner RP (2004) Encoding versus retrieval of spatial memory: double dissociation between the dentate gyrus and the perforant path inputs to CA3 in the dorsal hippocampus. Hippocampus 14:66-76.

Lee I, Rao G, Knierim JJ (2004) A double dissociation between hippocampal 
subfields: differential time course of CA3 and CA1 place cells for processing changed environments. Neuron 42:803-815.

Leung LS, Shen B (2004) Glutamatergic synaptic transmission participates in generating the hippocampal EEG. Hippocampus 14:510-525.

Leutgeb S, Leutgeb JK, Treves A, Moser MB, Moser EI (2004) Distinct ensemble codes in hippocampal areas CA3 and CA1. Science 305:1295-1298.

Marr D (1971) Simple memory: a theory for archicortex. Philos Trans R Soc Lond B Biol Sci 262:23-81.

Martinez CO, Do VH, Martinez Jr JL, Derrick BE (2002) Associative longterm potentiation (LTP) among extrinsic afferents of the hippocampal CA3 region in vivo. Brain Res 940:86-94.

McClelland JL, McNaughton BL, O’Reilly RC (1995) Why there are complimentary learning systems in the hippocampus and neocortex: insights from the successes and failures of connectionist models of learning and memory. Psych Rev 102:419-457.

McNaughton BL, Barnes CA (1977) Physiological identification and analysis of dentate granule cell responses to stimulation of the medial and lateral perforant pathways in the rat. J Comp Neurol 175:439-454.

McNaughton BL, Morris RGM (1987) Hippocampal synaptic enhancement and information storage within a distributed memory system. Trends Neurosci 10:408-415.

Meeter M, Murre JM, Talamini LM (2004) Mode shifting between storage and recall based on novelty detection in oscillating hippocampal circuits. Hippocampus 14:722-741.

Morris RG, Inglis J, Ainge JA, Olverman HJ, Tulloch J, Dudai Y, Kelly PA (2006) Memory reconsolidation: sensitivity of spatial memory to inhibition of protein synthesis in dorsal hippocampus during encoding and retrieval. Neuron 50:479-489.

Moser EI, Moser MB (2003) One-shot memory in hippocampal CA3 networks. Neuron 38:147-148.

Nakazawa K, Quirk MC, Chitwood RA, Watanabe M, Yeckel MF, Sun LD, Kato A, Carr CA, Johnston D, Wilson MA, Tonegawa S (2002) Requirement for hippocampal CA3 NMDA receptors in associative memory recall. Science 297:211-218.

O'Keefe J, Nadel L (1978) The hippocampus as a cognitive map. Oxford, UK: Clarendon.

O’Reilly RC, McClelland JL (1994) Hippocampal encoding, storage and recall: avoiding a trade-off. Hippocampus 4:661-682.

Orr G, Rao G, Houston FP, McNaughton BL, Barnes CA (2001) Hippocampal synaptic plasticity is modulated by theta rhythm in the fascia dentata of adult and aged freely behaving rats. Hippocampus 11:647-654.

Pavlides C, Greenstein YJ, Grudman M, Winson J (1988) Long-term potentiation in the dentate gyrus is induced preferentially on the positive phase of theta-rhythm. Brain Res 439:383-387.

Paxinos G, Watson C (1994) Stereotaxic atlas of the rat brain, Ed 2, plate 50. New York: Academic.

Pitkanen M, Sirvio J, Ylinen A, Koivisto E, Riekkinen P Sr (1995) Effects of NMDA receptor modulation on hippocampal type 2 theta activity in rats. Gen Pharmacol 26:1065-1070.
Przybyslawski J, Sara SJ (1997) Reconsolidation of memory after its reactivation. Behav Brain Res 84:241-246.

Rogers JL, Kesner RP (2003) Cholinergic modulation of the hippocampus during encoding and retrieval. Neurobiol Learn Mem 80:332-342.

Rolls E, Treves A (1998) Neural networks and brain function. New York: Oxford UP.

Rossato JI, Lia RM, Bevilaqua LR, Medina JH, Izquierdo I, Cammarota M (2006) Retrieval induces hippocampal-dependent reconsolidation of spatial memory. Learn Mem 13:431-440.

Sainsbury RS, Heynen A, Montoya CP (1987) Behavioral correlates of hippocampal type 2 theta in the rat. Physiol Behav 39:513-519.

Seidenbecher T, Laxmi TR, Stork O, Pape HC (2003) Amygdalar and hippocampal theta rhythm synchronization during fear memory retrieval. Science 301:846-850.

Singh HK, Ott T, Matthies H (1974) Effect of intrahippocampal injection of atropine on different phases of a learning experiment. Psychopharmacologia 38:247-258.

Thiel CM, Huston JP, Schwarting RK (1998) Hippocampal acetylcholine and habituation learning. Neuroscience 85(4):1253-1262.

Treves A, Rolls ET (1992) Computational constraints suggest the need for two distinct input systems to the hippocampal CA3 network. Hippocampus 2:189-199.

Treves A, Rolls ET (1994) Computational analysis of the role of the hippocampus in memory. Hippocampus 4:374-391.

Tronel S, Milekic MH, Alberini CM (2005) Linking new information to a reactivated memory requires consolidation and not reconsolidation mechanisms. PLoS Biol 3:e293.

Vanderwolf CH (1969) Hippocampal electrical activity and voluntary movement in the rat. Electroencephalogr Clin Neurophysiol 26:407-418.

Vanderwolf CH, Leung LW (1983) Hippocampal rhythmical slow activity. In: The neurobiology of the hippocampus. (Seifert W, ed). London: Academic.

Vazdarjanova A Guzowski JF (2004) Differences in hippocampal neuronal population responses to modifications of an environmental context: evidence for distinct, yet complementary, functions of CA3 and CA1 ensembles. J Neurosci 24:6489-6496.

Villarreal D, Do V, Haddad E, Derrick BE (2002) NMDA antagonists sustain LTP and spatial Memory: evidence for active processes underlying LTP decay. Nat Neurosci 5:48-52.

Wiig KA, Heynen AJ Bilkey DK (1994) Effects of Kainic acid microinfusions on hippocampal type 2 RSA (theta). Brain Res Bull 33:6727-6732.

Whishaw IQ (1972) Hippocampal electroencephalographic activity in the Mongolian gerbil during natural behaviors and in wheel running and conditioned immobility. Can J Psychol 26:219-239.

Whishaw IQ, CH Vanderwolf (1973) Hippocampal EEG and behavior: changes in amplitude and frequency of RSA (theta rhythm) associated with spontaneous and learned movement patterns in rats and cats. Behav Biology 8:461-484.

Wyble BP, Linster C, Hasselmo ME (2000) Size of CA1-evoked synaptic potentials is related to theta rhythm phase in rat hippocampus. J Neurophys 83:2138-2144. 